\title{
A COMMENT ON THE "EFFICIENT ALLOCATION OF RESOURCES IN A REGULATED AND UNIONIZED MONOPOLY"
}

In the April 1976 issue of this Journal Mirakhor suggested that an efficient allocation of resources is possible for a profit maximizing monopolist operating under regulatory and union constraints. This analysis may be extended by assuming the monopolist augments the factors of production by selecting technologies from a closed, exogenously determined, set of techniques. Under this additional constraint, efficient resource allocation implies that factor augmentation is solely determined by relative input costs, ceteris paribus. It can also be demonstrated that the innovational constraint accentuates the incentive for labor augmentation when the regulatory constraint is active, or it accentuates the incentive for capital augmentation when the union constraint is active.

Assume the monopolist operates with a production function:

(1) $q=f\left(a_{1} L, a_{2} K\right)$;

$$
\partial f / \partial L>0, \quad \partial f / \partial K>0
$$

where $L$ and $K$ represent the stock of labor and capital and where $a_{1}$ and $a_{2}$ represent technically determined augmentation coefficients. The coefficients are constrained by a concave innovational possibility frontier:

$$
T=g\left(a_{1}, a_{2}\right)
$$

where $T$ represents the total innovative effort for augmenting labor and capital. $a_{1}$ and $a_{2}$ are functionally related by a technically determined set of innovational choices. Concavity of the innovational possibility frontier reflects diminishing returns to innovation [2]. This firm also operates under a regulatory constraint where $s$ is the allowable rate of return on capital and $i$ the market cost of capital:

$$
p(q) q-w L \leq s K ; \quad s>i
$$

and a union constraint where $\hat{w}$ is the desired union wage and $w$ the market wage:

$$
p(q) q-i K \leq \hat{w} L ; \quad \hat{w}>w .
$$

Treating each constraint (2), (3), and (4) as an equality, profit maximization implies that the augmentation coefficients are related as:

$$
\frac{a_{2}}{a_{1}}=M R S I \frac{i K}{w L}\left[\frac{1-\lambda_{2}\left(\frac{s}{i}\right)-\lambda_{3}}{1-\lambda_{2}-\lambda_{3}\left(\frac{\hat{w}}{w}\right)}\right]
$$

where $M R S I\left[-d a_{2} / d a_{1}\right]$ is the marginal rate of substitution along the innovational possibility frontier and where $\lambda_{2}$ and $\lambda_{3}$ are independent Lagrangian multipliers for constraints (3) and (4), respectively. If $\lambda_{2}=\lambda_{3}=$ 0 then technical bias is solely determined by relative input costs, ceteris paribus. If $\lambda_{3}=0$ and the Averch-Johnson effect is active $\left[1-\lambda_{2}>1-\lambda_{2}(s / i)\right]$, the firm will tend toward overcapitalization by engaging technology to augment labor relative to capital. If $\lambda_{2}=0$ and the Zajac effect is active [1$\left.\lambda_{3}>1-\lambda_{3}(\hat{w} / w)\right]$, the firm will tend toward overlaborization by engaging technology to augment capital relative to labor.

Of particular interest here are the implications of technical bias when the regulatory and union constraints are effective. Three cases, parallel to Mirakhor's analysis, are examined:

CASE 1: The Averch-Johnson effect active.

In this case $\lambda_{2}>0$ and :

$$
\frac{1-\lambda_{2}\left(\frac{s}{i}\right)-\lambda_{3}}{1-\lambda_{2}-\lambda_{3}\left(\frac{\hat{w}}{w}\right)}<1
$$

which, according to equation (5), implies the firm will select a technology which augments labor more than capital. The union constraint $\left(\lambda_{3}>0\right)$ accentuates this incentive for 
relatively labor augmenting technology: ${ }^{1}$

(7) $1>\left[\frac{1-\lambda_{2}\left(\frac{s}{i}\right)}{1-\lambda_{2}}\right]$

$$
>\left[\frac{1-\lambda_{2}\left(\frac{s}{i}\right)-\lambda_{3}}{1-\lambda_{2}-\lambda_{3}\left(\frac{\hat{w}}{w}\right)}\right]
$$

CASE 2: The Zajac effect active.

In this case $\lambda_{3}>0$ and :

$$
\frac{1-\lambda_{2}\left(\frac{s}{i}\right)-\lambda_{3}}{1-\lambda_{2}-\lambda_{3}\left(\frac{\hat{w}}{w}\right)}>1
$$

which, according to equation (5), implies the firm will select a technology which augments capital more than labor. The union constraint $\left(\lambda_{2}>0\right)$ accentuates this incentive for relative capital augmenting technology: ${ }^{2}$

(9)

$$
\begin{aligned}
1<\left[\frac{1-\lambda_{3}}{1-\lambda_{3}\left(\frac{\hat{w}}{w}\right)}\right] \\
<\left[\frac{1-\lambda_{2}\left(\frac{s}{i}\right)-\lambda_{3}}{1-\lambda_{2}-\lambda_{3}\left(\frac{\hat{w}}{w}\right)}\right]
\end{aligned}
$$

$C A S E$ 3: Allocative Efficiency

In this case $\lambda_{2}>0, \lambda_{3}>0$, and:

$$
\frac{1-\lambda_{2}\left(\frac{s}{i}\right)-\lambda_{3}}{1-\lambda_{2}-\lambda_{3}\left(\frac{\hat{w}}{w}\right)}=1 \text {. }
$$

Likewise from equation (5), allocative efficiency implies that technical bias is solely determined by relative input costs, ceteris paribus. Consequently, if the regulatory com-

\footnotetext{
${ }^{1}$ Relationship (7) may formally be demonstrated through proof by contradiction. If we assume the inequalities associated with relationship (7) are reversed and prove this new relationship is false, relationship (7) is therefore proved valid. The contradictory relationship is shown to be false when $s / i>\hat{w} / w$ as will be the case when the Averch-Johnson effect is active and $\lambda_{2}<\lambda_{3}$ or $\lambda_{2}=\lambda_{3} ; \lambda_{2}>\lambda_{3}$ is an indeterminant solution.

${ }^{2}$ Relationship (9) may also be formally demonstrated through proof by contradicition. Here, the proof rests on $\hat{w} / w>s / i$ which will be the case when the Zajac effect is active and $\lambda_{2}>\lambda_{3}$ or $\lambda_{2}=\lambda_{3} ; \lambda_{2}<\lambda_{3}$ is an indeterminant solution.
}

mission views $\hat{w}$ as given and sets $s$ such that $s / i=\hat{w} / w$ then an efficient allocation of resources would result, as Mirakhor suggested, and competitive markets would determine specific technical biases.

Also note, the direction for factor augmentation is reversed when the regulated monopoly gains monopsony power in the labor market. Here, the union constraint becomes:

$$
\begin{aligned}
p(q) q-m K \leq & \bar{w} L ; \\
& \hat{w}>\bar{w}, \quad i<m<s .
\end{aligned}
$$

Maximizing profit subject to equations (1) and (2) and constraints (3) and (11), we obtain:

$$
\frac{a_{2}}{a_{1}}=\operatorname{MRSI} \frac{i K}{w L}\left[\frac{1-\lambda_{2}\left(\frac{s}{i}\right)-\lambda_{4}\left(\frac{m}{i}\right)}{1-\lambda_{2}-\lambda_{4}\left(\frac{\bar{w}}{w}\right)}\right]
$$

where $\lambda_{2}$ and $\lambda_{4}$ are independent Lagrangian multipliers for constraints (3) and (11), respectively. The regulated monopolist finds labor relatively less expensive now than when the union constraint (4) was dominant. Consequently, the monopolist will have less tendency to induce relatively labor augmenting technology: ${ }^{3}$

$$
\begin{aligned}
1> & {\left[\frac{1-\lambda_{2}\left(\frac{s}{i}\right)}{1-\lambda_{2}}\right] } \\
> & {\left[\frac{1-\lambda_{2}\left(\frac{s}{i}\right)-\lambda_{4}\left(\frac{m}{i}\right)}{1-\lambda_{2}-\lambda_{4}\left(\frac{\bar{w}}{w}\right)}\right] } \\
> & {\left[\frac{1-\lambda_{2}\left(\frac{s}{i}\right)-\lambda_{3}}{1-\lambda_{2}-\lambda_{3}\left(\frac{\hat{w}}{w}\right)}\right] }
\end{aligned}
$$

\section{A uburn University}

ALBERT N. LINK

\section{REFERENCES}

1. Mirakhor, Abbas, "Efficient Allocation of Resources in a Regulated and Unionized Monopoly." Southern Economic Journal, A pril 1976. 725-729.

2. Smith, V. Kerry, "The Implications of Regulation for Induced Technical Change." The Bell Journal of Economics and Management Science, Autumn 1974. 623-631.

${ }^{3}$ Relationship (13) may likewise be formally demonstrated through proof by contradiction. As in relationship (7), this proof rests on $s / i>\hat{w} / w$. 
Copyright of Southern Economic Journal is the property of Southern Economic Association and its content may not be copied or emailed to multiple sites or posted to a listserv without the copyright holder's express written permission. However, users may print, download, or email articles for individual use. 